\title{
Research on Measures to Improve the Innovation Performance of R\&D Investment in Smart Home Enterprises
}

\author{
Zhongying Zhao, Qingjun Meng, Yan Cai \\ School of Business, University of Hohai, Nanjing, China \\ Email: zzy1234598@163.com
}

How to cite this paper: Zhao, Z.Y., Meng, Q.J. and Cai, Y. (2018) Research on Measures to Improve the Innovation Performance of R\&D Investment in Smart Home Enterprises. Open Journal of Business and Management, 6, 890-899.

https://doi.org/10.4236/ojbm.2018.64065

Received: September 19, 2018

Accepted: October 15, 2018

Published: October 18, 2018

Copyright (@) 2018 by authors and Scientific Research Publishing Inc. This work is licensed under the Creative Commons Attribution International License (CC BY 4.0).

http://creativecommons.org/licenses/by/4.0/

\begin{abstract}
As the artificial intelligence industry is increasingly showing irreplaceable importance in people's production and life, the smart home furnishing industry, which belongs to the field of artificial intelligence, has become a new industry attracting great attention. Smart home furnishing enterprises are enterprises with strong requirements for innovation, whose products are mostly dependent on a large amount of $R \& D$ investment to maintain their core competitiveness. However, the smart home industry started late in China, which has problems such as insufficient market development and disordered industry standards. In order to improve the performance of innovation, enterprises need to increase their investment in $R \& D$, while a relatively stable environment is needed, and external support is relatively loose policies. This requires cooperation from companies, investors, governments and so on. This study will start from the current situation of the smart home industry, study different factors affecting the innovation performance of the R\&D investment of smart home enterprises, and put forward suggestions from different perspectives.
\end{abstract}

\section{Keywords}

Smart Home, Artificial Intelligence, R\&D Investment, Innovation Performance

\section{Introduction}

\subsection{Opportunities for the Development of Smart Home Industry}

Since the 21st century, electronic computer technology, information technology and other new and high technologies have been greatly developed. The artificial 
intelligence industry, as an open and shared industry based on big data technology, is gradually emerging in combination with the development of the Internet of Things and cloud computing technology. With the development of economy and the diversification of human needs, artificial intelligence gradually includes intelligent system, intelligent identification, cloud technology and other technical fields, among which the smart home industry is an industrial field with great development potential and has been attracting a lot of attention.

Smart home industry is in line with people's pursuit of high efficiency, intelligence and modernization. At the same time, smart home is also gradually entering the aging society in China in the field of elderly care to play an essential role in saving the family's pension expenses. Xiaomi Technology has opened smart home experience stores in some cities, and its products, such as Xiaomi smart lamp and Xiaomi smart TV, have attracted certain consumers and been widely praised [1]. However, the intelligent home furnishing industry is not fully developed in China, and the industry is not mature yet, which has certain investment risks. In November 2017, China Light Industry Association and China Home Appliances Research Institute jointly announced the launch of the smart home group standard development work. With the development of industry standards, the smart home industry will move forward toward standardization, with vigorous vitality.

\subsection{Development Status of Smart Home Enterprises in China}

Smart home industry in western countries, such as Germany and the United States, has a long history. Their markets have been relatively mature. Compared with more mature markets and stronger capital investment abroad, "smart home" is still a very vague concept for the public in China [2]. However, with the improvement of Chinese people's living standards and the improvement of demand for smart products, China with a huge population base is expected to become one of the largest smart home markets in the future [2]. China's smart home industry started late, but its huge number of consumers and high consumption power determine its great potential for development. Based on the analysis of the total assets of the main listed companies in the smart home industry in the past three years, the following characteristics of China's smart home industry can be obtained:

1) There is a large gap between the size and scale of enterprises, and most of them are small and medium-sized enterprises. Most of the listed companies are also small and the industry has yet to establish a unified standard, while the product quality is mixed and innovation is insufficient, price is expensive [3].

2) Lack of industrial leading enterprises. At present, though Xiaomi, TCL, Midea and other large enterprises have been exploring the market of smart home, the market isn't the main areas for their development. It is still some way for these enterprises from becoming the industry leader [2].

3) The industry is in the initial stage, and there are many potential risks. The development of smart home industry is still immature [3]. Up to now, there is 
no popular product in the whole industry. Market risk and technical risk cannot be ignored. However, most smart home enterprises are still in sustainable development, and many enterprises are still in the rising stage of total assets. For example, the total assets of Jinfu Technology in 2016 and 2017 maintained an amazing $86 \%-100 \%$ annual growth rate, and the total assets of most listed companies maintained an annual growth rate of $20 \%-45 \%$ in the past three years, indicating that the whole industry has great development potential.

\subsection{There Is a Complex Relationship between R\&D Investment and Innovation Performance}

"Technology is the primary productive force", and investment in science and technology research is an important force to promote the development of the national economic development. For high-tech companies, R\&D investment is even more important.

The increasing of $\mathrm{R} \& \mathrm{D}$ investment is to improve the innovation performance, but a substantial increase in $R \& D$ investment does not mean a year-on-year increase in innovation performance. $R \& D$ investment should be transformed into innovative performance, and it must go through certain processes, such as the conversion of $\mathrm{R} \& \mathrm{D}$ investment into new technology, the conversion of new technology into new products or upgraded products, the conversion of new products or upgraded products into market sales, and the conversion of market sales into operating income, the value-added of the brand and the increase of the intangible assets of the enterprise. These processes are highly susceptible to influences from different aspects such as the market, technology, policy, and internal finance.

The ratio of $R \& D$ intensity (Ratio of $R \& D$ investment to operating income) and $\mathrm{R} \& \mathrm{D}$ personnel to total number of companies are not directly proportional to operating income. In 2017, Midea Group and TCL Group's R\&D intensity were $3.53 \%$ and $4.23 \%$ respectively, while Wanxing Technology's R\&D investment was $19.79 \%$. Companies with little R\&D intensity may be industry giants or ordinary small businesses with low operating income. This shows that $\mathrm{R} \& \mathrm{D}$ investment innovation performance is affected by many factors, which will be transformed into risks to a certain extent, and hinder the smooth transition of $\mathrm{R} \& \mathrm{D}$ investment into innovation performance.

\subsection{Literature Review}

The smart home industry is not a hot new industry in China, nor does it have a popular product that really opens up the market. Therefore, the research focusing on the smart home industry is not much compared with other industries, and the research focusing on improving its innovation performance is also less. However, the smart home industry can be classified into high-tech industries, and there are many researches on the R\&D investment benefits of high-tech enterprises. 


\section{Factors Influencing the Innovation Performance of Smart Home Enterprises in R\&D Investment}

\subsection{Market Factors [1]}

The development of intelligent household products is the concrete manifestation of human society's intelligent trend, and the potential market is very broad. However, the vast potential market is not equal to the vast market, and the exploration process of potential customers still contains great risks.

First of all, consumers still know little about the concept of smart home products, and their impression is solidified in China. To open the market, enterprises should first use proper marketing to establish a good image of products and brands.

Secondly, at present, the overall market atmosphere of smart home market is not conducive to the sustainable development of the industry. Although there are many smart home furnishing enterprises, they are all going their own way in terms of production standards, and the quality of products is not standardized and unified. In the long run, there may be undesirable atmosphere and reduce consumers' impression of the industry as a whole.

At the same time, market risks should be taken into account that domestic consumers have little contact with such intelligent products, and it is difficult for them to have opportunities to experience and generate consumption demand. As the use of smart home products needs to go through a series of tedious processes such as replacing existing furniture, installing systems and implanting sensors, it will restrain consumers' desire to consume to some extent.

\subsection{Technical Factors}

The R\&D of new technology is a risk activity. If the consumer demand is not accurately grasped and the technical talents are not sufficiently stimulated, the investment in technology R\&D will not yield its equivalent benefits. R\&D of new technologies is the lifeline of the smart industry. To maintain the core competitiveness, enterprises need to continuously invest a large amount of technology $\mathrm{R} \& \mathrm{D}$ costs and attract high-end talents in the industry.

When making the decision to invest in R\&D technology, we should consider whether the new technology is matched with the market demand, and the market tends to accept the products with high demand rather than blindly pursue the products with high and sophisticated technology [4]. In the process of R\&D, we should pay attention to the following aspects. First, the capital cost of technology investment and the high cost may lead to financial risks and internal instability. Secondly, whether new technologies can be smoothly applied to products, that is, new technologies can be successfully commercialized and achieve expected economic benefits. Thirdly, the protection of trade secrets and intellectual property rights should be paid attention to in the market competition. The imprecise protection mechanism will lead to the leakage of new technologies and the competition will seize the opportunity. 
The risks brought by technical factors include not only the above-mentioned financial losses, but also the damage to the value of the enterprise. Such as the improper decision-making and encouragement lead to the outflow of high-level technical talents, and the internal stability of the enterprise and the enthusiasm of employees are greatly affected.

\subsection{Policy Factors (Such as Taxes)}

Policy environment is the basic factor of enterprise survival and development. For the smart home industry, which is dominated by small and medium-sized enterprises, it is more necessary to keep an eye on the changes and trends of policies. Due to the small business income, the preferential tax will greatly improve the development enthusiasm of small and medium-sized enterprises. The subsidy policy can also give great help in terms of capital, operation and technical support. The support of policies can help small and medium-sized enterprises to develop and expand, but the sudden change of policies can also affect their business development to some extent.

The outline of China's 13th five-year plan proposes to speed up the construction of new cities, promote the development of big data and Internet of Things, and build smart cities in the process of "building a harmonious and livable city". The so-called smart city refers to connecting the whole city with the Internet of Things and the Internet mainly through the massive application of the new generation of information technology such as sensors, so as to improve people's production and living standards. The smart home industry plays a supporting role in promoting the construction of smart cities. In the future, it may become the object of policy support. The China's State Council issued the guidance on actively promoting the "Internet plus" initiative, which also emphasizes the development of smart cities, which is the inherent policy advantage of the smart home industry [5].

\subsection{The Financial Management}

There are certain risks in financial management and cost control. The smart home industry is dominated by small and medium-sized private enterprises, and most of the listed companies are still in the upswing. Many small and medium-sized enterprises have inherent deficiencies, with limited funds and resources, while their financial control and internal management work are not in place, which can easily lead to financial risks and affect the innovation performance of enterprises.

Innovation performance is easily affected by the budget mechanism in enterprise financial management. The development of new technology needs to fully and truly estimate its financing cost, R\&D investment, economic benefits, technology and environmental benefits, and achieve strict planning and scientific decision-making. The inaccuracy of the budget for new technology development will affect the smooth development and even cause the waste of funds and the 
delay of the progress. At the same time, the budget needs certain supervision during the promotion process to prevent problems such as improper use of investment funds or stagnant progress.

Furthermore, the internal management level of an enterprise will also affect the improvement of innovation performance. The auditing system and the supervision system are indispensable to the smoothly operation of internal management mechanism. However, the mature auditing and supervision system has not been established in most small and medium-sized smart home enterprises. An unsound audit system cannot be found and corrected in time when there are problems in the internal financial affairs of the enterprise. It is impossible for such system to maximize the capital utility, accurately detect the flow of funds and breed potential financial risks.

\section{The Way to Improve the Innovation Performance of the R\&D Investment of Smart Home Enterprises}

\subsection{Enterprise Perspective}

\subsubsection{Accurately Grasping Market Demand and Paying Attention to Brand Construction}

The production and operation decision of an enterprise should be based on fully investigating the actual demand of consumers. In terms of what to produce and how much to produce, especially in the development of new products, special attention should be paid to market research and issue consumer surveys to reduce the risks in the decision-making of production and operation. Series of intelligent washing machines developed by TCL, such as variable frequency intelligent control and full-screen touch control, accurately grasp the demands that consumers cannot meet for existing washing machines. TCL has developed products with functions such as ultra-quiet, intelligent power cut and intelligent children's lock, etc., meeting consumers' demand for laundry time control and energy consumption control, and the price is relatively close to the public, which has been widely praised. The production decision that ignores market demand is bound to bring risk.

Enterprises should also establish a good brand impression in consumers' mind through proper marketing, and at the same time, use brand strategies to make consumers have some understanding of the concept of smart home products and stimulate their consumption desire. Because of the low popularity of smart home products in China, many consumers do not have access to smart home. Therefore, enterprises can adopt the offline store experience marketing strategy and build a large number of stores to guide consumption and increase demand. The best way to resist the shortage of demand is to create the market and create demand.

\subsubsection{Developing Core Technologies and Improving the Efficiency of Technology R\&D}

Developing core technologies is the fundamental way to maintain core competi- 
tiveness, as well as an effective way to ensure the vitality of enterprise innovation and reduce investment risks. According to the product life cycle theory, products in the rising period of development need to highlight the core technology to attract customers; products in the mature period can constantly improve technology and process, consolidate and upgrade core technology to retain consumers [4].

The development of new technology should be paid attention to before, during and after the event. When making decisions about whether or not to invest in new technologies or which new technologies to invest in, requirements should be clarified and reasonable predictions should be made. In the process of technology $R \& D$, supervisory teams should be set up to clarify the accountability mechanism and the direction of R\&D investment as far as possible. Keep up with the progress and direction of technology R\&D at any time. The progress of technology development should be compared with the expected plan at any time, and remedial measures should be taken in case of any deviation. After the $R \& D$, the feedback of the whole $R \& D$ process should be well done, the gain and loss should be summarized, and the risk transfer should be done in a timely manner. In the whole process of $\mathrm{R} \& \mathrm{D}$, scientific decision-making, transparent supervision, complete budget and error correction should be achieved as far as possible. In the case of less detours and wrong roads, we will effectively improve the efficiency of technology R\&D and win opportunities.

\subsubsection{Strengthening Internal Control}

Internal control is a very important part of modern enterprise management. A good internal control system can not only realize the effective and rational allocation of internal resources, but also maximize the utilization of resources and improve the overall efficiency and operational efficiency of the enterprise. Strengthening internal control can be divided into internal risk control, internal accounting control, internal business process control, internal financial activity control, and internal information control [6].

In terms of accounting control, enterprises should strengthen the management and supervision of financial activities and accounting activities, implement a comprehensive budget for production operations, strictly establish budget plans, prepare budget tables based on actual conditions, and implement budget plans in layers to achieve cost reduction. Control internal costs and maximize the use of funds.

What also needs attention is the internal risk control aspect, needs to establish the risk early warning and the response mechanism. The smart home industry is in the period of development, with potential risks of various kinds [6]. Enterprises should establish a reasonable risk assessment system and a flexible risk response mechanism, and respond to different risks with different strategies to make the risks controllable. Establish smooth information communication channels in all departments of the enterprise, reduce information asymmetry, so that when risks come, the enterprise can be united front up and down, and make 
timely response.

\subsection{Government Perspective}

\subsubsection{Improving Industrial Support Policies}

The supporting strength and the direction of the policy play a leading role in the development of the industry. Measures such as tax incentives, policy subsidies and low-threshold long-term loans for small businesses can strongly boost the development of the whole industry. The implementation of appropriate preferential tax policies can stimulate the initiative of smart home industry in its infancy. Appropriate subsidy policies can reduce the cost of production.

The financing difficulties of small and medium-sized enterprises sometimes hinder their growth. Policies can guide the improvement of China's financing institution system, help the development of financing loan business of financial institutions, such as trust institutions (in addition to commercial banks) and regulate private loans. Help improve the credit guarantee system of small and medium-sized enterprises, so that small and medium-sized enterprises have the opportunity to use commercial credit loans with low threshold, low fee and easy access, diversifying financing channels and reducing their financing difficulty and cost.

\subsubsection{Guiding the Industry Associations and Other Organizations to Participate in Enterprise Innovation}

The domestic smart home furnishing industry is in the starting state, and the overall industry is relatively immature. There is a lack of enterprises with real strong strength as industry leaders. The industry production standards in various aspects cannot be unified, which is quite chaotic, and which greatly hinders the overall development of the industry. The government should play a macro-control role here; to cooperate with and negotiate with industry associations, or help them to formulate unified industry standards, regulate production and operation, introduce product development and production to the road of regulation, curb vicious competition and bad competition, curb the blind pursuit of short-term interests, and guide the long-term healthy and sustainable development of the industry as a whole.

The guiding role of the government can also be reflected in the education industry to strengthen the cultivation of AI professionals and promote the technological innovation of smart home enterprises. Help the industry to establish a good reputation and improve the public awareness of the product industry.

\section{Conclusion}

According to the product life cycle theory, the smart home industry is still in the rising stage of development. Although there are many problems, insufficient development and small customer groups, it caters to the trend of human society's intelligence and modern life's pursuit of high efficiency, and has a broad development prospect and potential market. In the high-tech industry, R\&D invest- 
ment is the lifeline for the sustainable development of enterprises, but a large amount of $\mathrm{R} \& \mathrm{D}$ investment often does not mean equal returns. In the smart home industry, the innovation performance of R\&D investment is affected by various factors. Under certain conditions, these factors will be transformed into unstable factors and even generate risks. In order to improve the enterprise's innovation performance, it is necessary to analyze these factors and put forward countermeasures. In the next three to five years, the industry standards of smart home industry will be introduced soon, and the "13th Five-Year Plan" and the China Manufacturing 2025 plan will help its development [7]. In order to reduce the risk of smart home industry; first of all, "open source" should be adopted. Smart home enterprises themselves should grasp the market demand, develop core technologies and strive to open up the market. The government should guide the standardization of the industry in a macroscopic way and perfect the supporting policies. The smart home industry has unlimited potential and will gradually become a part of people's life with the promotion of "smart city".

\section{Fund Project}

2018 "Project of the National College Student Innovation and Entrepreneurship Training Program" of Hohai University: "Analysis of the Complex Relationship between R\&D Investment and Innovation Performance of Artificial Intelligence Companies" (No. 69).

\section{Conflicts of Interest}

The authors declare no conflicts of interest regarding the publication of this paper.

\section{References}

[1] Chen, Z.K. (2017) Intelligence Support for Domestic Competition Strategies of Smart Home Enterprises. Nanjing University, Nanjing. (In Chinese)

[2] Wu, L.H., Yang, W. and Meng, Y.J. (2014) Analysis of the Development Status of Smart Home Market at Home and Abroad. Modern Telecommunications Science and Technology, 44, 71-74. (In Chinese)

[3] Zhang, X.X., Yuan, Y. and Zhan, Y. (2018) On the Prospect of Smart Home Application. Information Recording Materials, 19, 127-128. (In Chinese)

[4] Zong, M.H. (2001) Enterprise Technology Risk and Its Analysis. Journal of Kunming University of Science and Technology (Natural Science), 2001, 118-122. (In Chinese)

[5] The State Council of the People's Republic of China (2017) Guidelines of the State Council of the People's Republic of China and the State Council on Deepening the "Internet + Advanced Manufacturing Industry" to Develop the Industrial Internet. http://www.gov.cn/zhengce/content/2017-11/27/content_5242582.htm

[6] Zhu, M.Q. (2005) Risk Analysis and Countermeasure Research on Commodity Housing Investment. Wuhan University, Wuhan. (In Chinese)

[7] The State Council of the People's Republic of China (2015) Notice of the State 
Council of the People's Republic of China and the State Council on Printing and Distributing. Made in China 2025.

http://m.mof.gov.cn/zcfb/201505/t20150519_1233751.htm 